\title{
ZPK/DLK, a Mitogen-Activated Protein Kinase Kinase Kinase, Is a Critical Mediator of Programmed Cell Death of Motoneurons
}

\author{
Aki Itoh, ${ }^{1,2}$ Makoto Horiuchi, ${ }^{1,2}$ Kouji Wakayama, ${ }^{1,2}$ Jie Xu, ${ }^{2}$ Peter Bannerman,,${ }^{2,3}$ David Pleasure, ${ }^{1,2}$ and Takayuki Itoh ${ }^{1,2}$ \\ ${ }^{1}$ Department of Neurology, University of California, Davis, School of Medicine, Sacramento, California 95817, ${ }^{2}$ Institute for Pediatric Regenerative \\ Medicine, Shriners Hospitals for Children Northern California, Sacramento, California 95817, and ${ }^{3}$ Department of Cell Biology and Human Anatomy, \\ University of California, Davis, Davis, California 95616
}

Activation of mitogen-activated protein kinase pathways is critically involved in naturally occurring programmed cell death of motoneurons during development, but the upstream mediators remain undetermined. We found that mice deficient in ZPK, also called DLK (ZPK/DLK), an upstream kinase in these pathways, have twice as many spinal motoneurons as do their wild-type littermates. Nuclear HB9/MNX1-positive motoneuron pools were generated similarly in the spinal cord of both ZPK/DLK-deficient and wild-type embryos. Thereafter, however, significantly less apoptotic motoneurons were found in ZPK/DLK-deficient embryos compared with wild-type embryos, resulting in retention of excess numbers of motoneurons after birth. Notably, these excess motoneurons remained viable without atrophic changes in the ZPK/DLK-deficient mice surviving into adulthood. Analysis of the diaphragm and the phrenic nerve revealed that clustering and innervation of neuromuscular junctions were indistinguishable between ZPK/DLK-deficient and wild-type mice, whereas the proximal portion of the phrenic nerve of ZPK/DLK-deficient mice contained significantly more axons than the distal portion. This result supports the hypothesis that some excess ZPK/DLK-deficient motoneurons survived without atrophy despite failure to establish axonal contact with their targets. This study provides compelling evidence for a critical role for ZPK/DLK in naturally occurring programmed cell death of motoneurons and suggests that ZPK/DLK could become a strategic therapeutic target in motor neuron diseases in which aberrant activation of the apoptogenic cascade is involved.

\section{Introduction}

During development, $\sim 50 \%$ of motoneurons generated are eliminated. This process, which is referred to as naturally occurring programmed cell death (NPCD) (Hamburger, 1975; Oppenheim, 1991), occurs in a strictly reproducible temporal and spatial pattern (Yamamoto and Henderson, 1999) and is essential for quantitative neuron-target matching. The molecular mechanisms underlying motoneuron NPCD have been intensively studied, yielding identification of a number of muscle-derived and other tissue-derived trophic molecules for motoneurons (Oppenheim, 1996). In general, insufficient supply of these molecules elicits activation of mitogen-activated protein kinase (MAPK) pathways, particularly the c-Jun $N$-terminal kinase (JNK, also referred to as stress-activated protein kinase) pathway

\footnotetext{
Received Nov. 10, 2010; revised Feb. 19, 2011; accepted March 23, 2011.

Author contributions: A.I. and T.I. designed research; A.I., M.H., K.W., J.X., P.B., and T.I. performed research; A.I. and T.I. analyzed data; A.I., D.P., and T.I. wrote the paper.

This work was supported by research fellowships from Shriners Hospitals for Children (to A.I. and M.H.), a research grant from Shriners Hospitals for Children (to A.I.), and National Institute of Health Grant NS025044 (to D.P. and T.I.). We thank Grete Adamson, Patricia Kysar, and Emma Lee at Electron Microscopy Laboratory, Department of Medical Pathology and Laboratory Medicine, for excellent technical supports for plastic-embedded tissue sections. The authors declare no competing financial interests.

Correspondence should be addressed to Dr. Takayuki Itoh, 601A Shriners Hospitals for Children Northern California, 2425 Stockton Boulevard, Sacramento, California 95817. E-mail: takito@ucdavis.edu.

DOI:10.1523/JNEUROSCI.5947-10.2011

Copyright $\odot 2011$ the authors $\quad 0270-6474 / 11 / 317223-06 \$ 15.00 / 0$
}

in neurons, and eventually results in motoneuron apoptosis through the intrinsic apoptotic pathway (Putcha and Johnson, 2004). The MAPK signaling cascade forms a three-tiered phosphorelay module consisting of MAPKs and their upstream kinases, MAPK kinases and MAPK kinase kinases (MAP3Ks) (Gallo and Johnson, 2002). Some MAP3Ks at the apical level are collectively termed mixed lineage kinases (MLKs), because their catalytic domain is a hybrid of serine/threonine and tyrosine kinases. Involvement of MLKs in apoptosis of motoneurons has been suggested by pharmacological studies using the MLK inhibitors, 3,9-bis[(ethylthio)methyl]-K-252a (CEP-1347/KT7515) and its derivative bis-isopropylthiomethyl-K-252a (CEP-11004) (Glicksman et al., 1998; Maroney et al., 1998; Murakata et al., 2002). Because these compounds inhibit a relatively broad range of the MLK family (Murakata et al., 2002; Chen et al., 2008) and activate Akt through an MLK-independent pathway (Roux et al., 2002), the identity of the MLK member that mediates activation of MAPK pathways leading to motoneuron NPCD remains an open question.

ZPK (also known as DLK, MUK, and MAP3K12; ZPK/DLK hereafter), a member of the MLK family, is most abundantly expressed in developing nervous tissues, thus suggesting a distinctive role in neural development (Holzman et al., 1994; Reddy and Pleasure, 1994; Fan et al., 1996; Hirai et al., 1996). Indeed, ZPK/DLK is known to regulate migration of immature neocortical neurons (Hirai et al., 2002, 2006). Recent studies using Cae- 


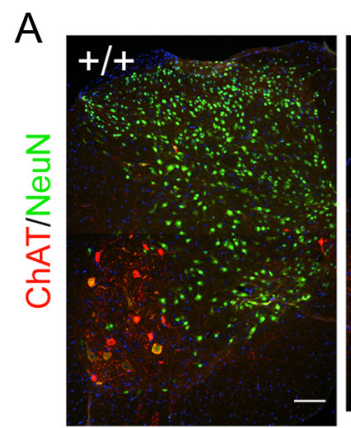

B

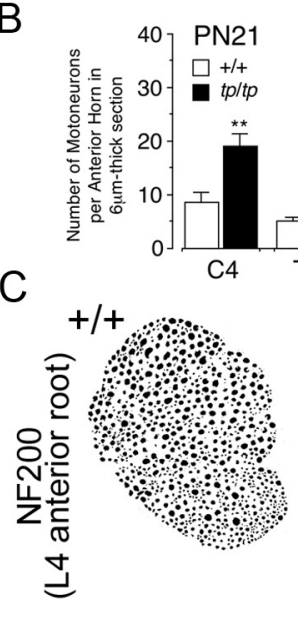

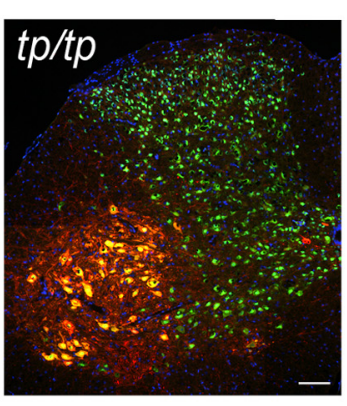
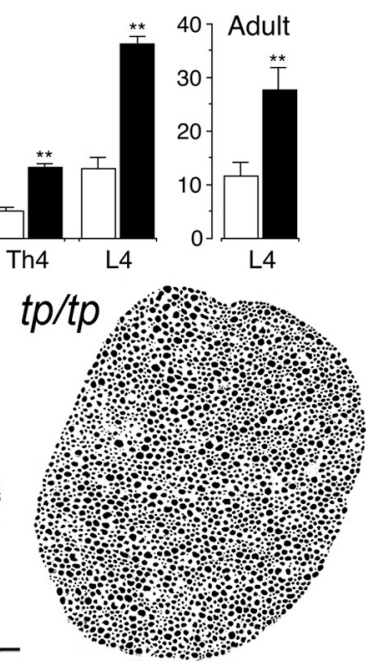

D

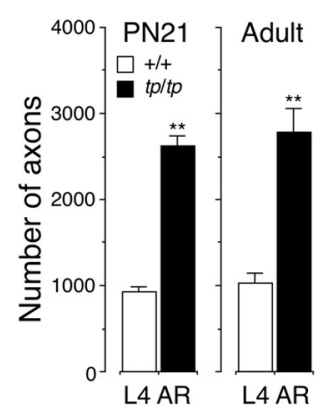

$E$
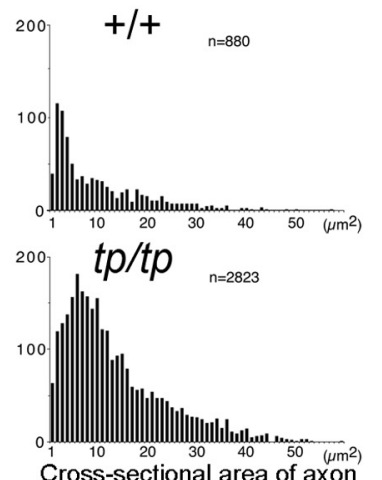

F
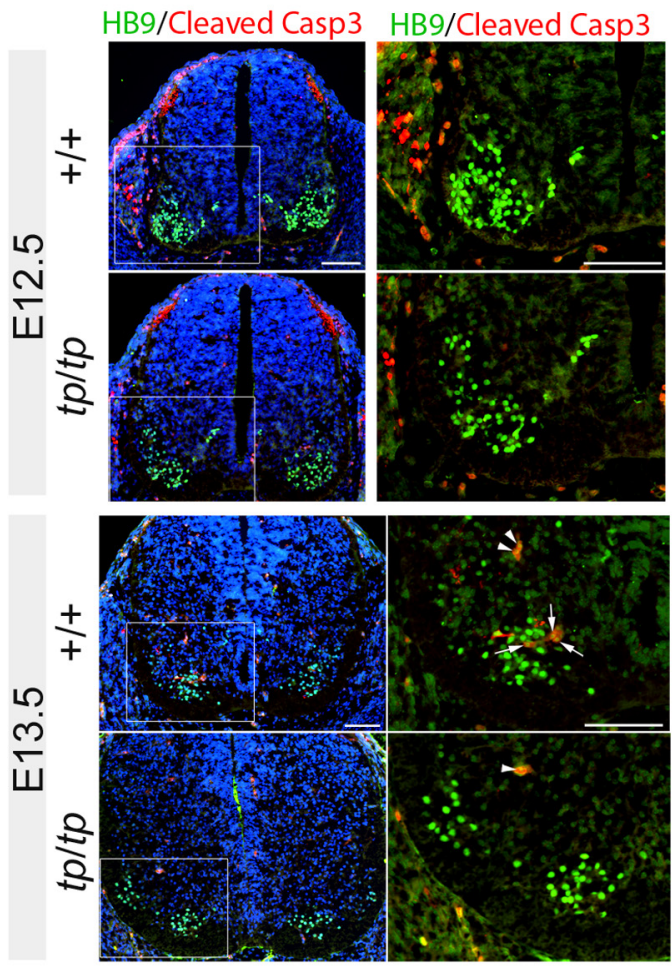

Figure 1. ZPK/DLK-deficient mice have more than twice as many spinal motoneurons as do wild-type mice. $\boldsymbol{A}$, Six-micrometer-thick cross-sections of the L4 spinal segments from wild-type $(+/+)$ and ZPK/DLK-deficient (tp/tp) mice at PN21 were immunolabeled for choline acetyltransferase (ChAT, red) and neuron-specific nuclear protein (NeuN, green). Motoneurons were identified as a ChAT ${ }^{+}$neuronal subset (yellow to red). B, Quantitative analysis of motoneurons in the (4 (fourth cervical), Th4 (fourth thoracic), and L4 spinal segments of wild-type and ZPK/DLK-deficient mice at PN21 and in adulthood. Motoneurons with visible nucleoli were counted in at least nine sections per animal, and the average number of motoneurons per section of the anterior horn on one side was calculated. At least three animals per genotype were examined in each age group. C, Axons in the L4 anterior root were also increased in number in ZPK/DLK-deficient mice. Representative confocal images of NF200-positive axons (inverted) in the L4 anterior roots from wild-type and ZPK/DLK-deficient mice are shown. D, Quantitative analysis of axon numbers in the L4 anterior roots (AR) from PN21 and adult mice as in $\boldsymbol{B}$. $\boldsymbol{E}$, A representative set of frequency histograms revealed that axons were increased in the entire range of axon sizes in ZPK/DLK-deficient mice at PN21. $\boldsymbol{F}$, Motoneuron NPCD was reduced in ZPK/DLK-deficient mice. The lumbar spinal segments from wild-type $(+/+)$ and ZPK/DLK-deficient (tp/tp) embry0s at E12.5 and E13.5 were immunolabeled for HB9 (green) and cleaved caspase-3 (red). Nuclei were counterstained with 4,6-diamidino-2-phenylindole (blue). The clusters of HB9-positive cells (boxed areas) were enlarged in the right column. At E13.5, cleaved caspase-3-positive cells were frequently observed in the HB9-positive motoneuron cluster of the wild-type spinal cord (arrows). These cells had pyknotic nuclei typical of cells undergoing apoptosis. Arrowheads indicate apoptotic cells outside of the motoneuron clusters. ${ }^{* *} p<0.01$ (unpaired $t$ test). Scale bars, $100 \mu \mathrm{m}$.

norhabditis elegans and Drosophila melanogaster further revealed that their ZPK/DLK homologues (named DLK-1 and Wallenda, respectively) positively regulate terminal formation by presynaptic neurons during development (Nakata et al., 2005; Collins et al., 2006) and promote axon regeneration (Hammarlund et al., 2009), as well as Wallerian degeneration (Miller et al., 2009), after axonal injury. Moreover, as a molecular mechanism underlying these conserved functions of ZPK/DLK in neurons, DLK-1 has been shown to regulate local protein synthesis in axon terminals by enhancing mRNA stability (Yan et al., 2009). We also demonstrated recently that ZPK/DLK promotes axonal regeneration of mammalian primary sensory neurons using ZPK/DLK-deficient mice (Itoh et al., 2009). Here, further analysis of these mice unexpectedly revealed a critical role for ZPK/DLK in NPCD of motoneurons.

\section{Materials and Methods}

$Z P K / D L K$-deficient mice. ZPK/DLK-deficient mice were derived from the gene-trap embryonic stem cell clone RRN366 (BayGenomics) as reported previously (Itoh et al., 2009). In this study, mice of both genders were used in conformity with a protocol approved by the Institutional Animal Care and Use Committee of the University of California Davis.
Reagents and chemicals. All reagents were purchased from either Sigma or Invitrogen, unless otherwise specified.

Immunohistochemistry. Mice were perfusion-fixed with $4 \%(\mathrm{w} / \mathrm{v})$ paraformaldehyde in PBS, as reported previously (Itoh et al., 2009), except that embryos were immersion-fixed in the same fixative overnight. Tissue sections $6 \mu \mathrm{m}$ thick were prepared by a cryostat (CM1950; Leica Microsystems); rinsed in PBS; incubated for $30 \mathrm{~min}$ at room temperature in a blocking solution containing $0.4 \%(\mathrm{w} / \mathrm{w})$ Triton X-100, $10 \%(\mathrm{v} / \mathrm{v})$ donkey serum, $15 \mathrm{~mm}$ HEPES, $0.02 \%(\mathrm{w} / \mathrm{v})$ sodium azide in $1 \times \mathrm{mini}$ mum essential medium; and incubated with primary antibodies in the blocking solution overnight at $4^{\circ} \mathrm{C}$. The following primary antibodies were used: rabbit monoclonal anti-cleaved caspase-3 (1:100; Cell Signaling Technology), goat polyclonal anti-choline acetyltransferase (AB144, 1:100; Millipore), mouse monoclonal anti-NeuN (MAB377, 1:100; Millipore), mouse monoclonal anti-HB9 (or MNR2; 81.5C10, 1:25, hybridoma supernatant; Developmental Studies Hybridoma Bank), rabbit antiserum against anti-NF-200 (N4142, 1:500; Sigma), and rat monoclonal anti-myelin basic protein (MBP) (NB600-717, 1:20; Novus Biologicals). Then, the sections were washed with PBS, incubated for $1 \mathrm{~h}$ in appropriate rhodamine, DyLight 488, or DyLight 549-conjugated secondary antibodies (1:500; Jackson Immunoresearch) at room temperature, and mounted with ProLong Gold antifade reagent with 4,6-diamidino-2phenylindole (Invitrogen). 
Diaphragms were processed as whole mounts in situ after fixation in $2 \%(\mathrm{w} / \mathrm{v})$ paraformaldehyde in PBS at $4^{\circ} \mathrm{C}$ overnight. The fixed diaphragms were incubated in $0.1 \mathrm{M}$ glycine in PBS, pH 7.3, for $30 \mathrm{~min}$ at room temperature, blocked in the blocking solution containing tetramethylrhodamine-conjugated $\alpha$-bungarotoxin $\left(\mathrm{T} 1175,10^{-8} \mathrm{M}\right.$; Invitrogen) for $1 \mathrm{~h}$, incubated in $100 \%$ methanol at $-20^{\circ} \mathrm{C}$ for $7 \mathrm{~min}$ for permeabilization, rinsed three times in $0.5 \%$ Triton-X in PBS, and then incubated with the primary antiserum for NF200 at $4^{\circ} \mathrm{C}$ overnight. The tissues were rinsed three times in $0.5 \%$ Triton- $\mathrm{X}$ in PBS, incubated with a secondary antibody at $4^{\circ} \mathrm{C}$ overnight, and mounted on slide glasses after rinsing in $0.5 \%$ Triton- $\mathrm{X}$ in PBS.

Quantitative histological analysis. Digitized fluorescent images were captured with a fluorescent microscope equipped with the Desk Scanning Unit (BX61; Olympus) and imaging software (Slidebox; Olympus). Numbers of neurons per $6-\mu \mathrm{m}$-thick cross-sections were counted in at least nine sections at a $60-\mu \mathrm{m}$-interval per tissue. At least three mice were analyzed in each genotype group. To quantify axon numbers, $6-\mu \mathrm{m}$-thick transverse sections of nerves were double-stained with anti-MBP and anti-NF200. Optical sections of confocal fluorescence images were acquired using a $60 \times$ oil objective (TE2000-E, numerical aperture 1.40; Nikon). NF200-positive axons were counted in digitally processed, single-channel, 8 -bit fluorescence images using ImageJ software (http://rsbweb.nih.gov/ij/). The myelinated axon numbers obtained by this method were generally very similar to those obtained by counting in semithin sections, which validated accuracy of this quantitative analysis.

Semithin sections of the phrenic nerves. Phrenic nerves were fixed with Karnovsky's fixative (2\% paraformaldehyde and $2.5 \%$ glutaraldehyde in $0.08 \mathrm{M}$ phosphage, $\mathrm{pH} 7.3-7.4$ ), secondary fixed in $2 \%$ osmium tetroxide, and embedded in epoxy resin polymerized at $65-70^{\circ} \mathrm{C}$. Sections $(1-\mu \mathrm{m}-$ thick) were prepared with an ultramicrotome (Leica Ultracut UCT) and stained with methylene blue and azure B. High-magnification images were taken with a microscope (BX61; Olympus) equipped with a digital camera (DP71; Olympus) and imaging software (DPController and DPManager).

Statistical analysis. Data are presented as means $\pm 1 \mathrm{SD}$ of at least triplicate experiments. Welch's unpaired $t$ test for unequal variances was used to determine the significance of differences between the two experimental groups. Otherwise, $p$ values were calculated by ANOVA followed by the Bonferroni/Dunn post hoc test.

\section{Results}

\section{Excess motoneurons persist in ZPK/DLK-deficient mice}

ZPK/DLK-deficient mice were born alive, but most died by the fourth postnatal week with only a few surviving to adulthood (Itoh et al., 2009). Although there were no gross anatomical abnormalities in the spinal cord segments and associated peripheral nerves of ZPK/DLK-deficient mice, ZPK/DLK-deficient spinal cords contained significantly more motoneurons positive for choline acetyltransferase than wild-type spinal cords at postnatal day (PN)21 and 6 months (Fig. 1). Correspondingly, there were 2.8-fold more axons in the ZPK/DLK-deficient fourth lumbar (L4) anterior root than in the wild-type L4 anterior root at PN21, and 2.7-fold more at 6 months. Based on the size distribution of myelinated axons in the L4 anterior root, this increase in number was unlikely to be restricted to a specific motoneuron subset (Fig. 1E).

\section{Motoneuron NPCD is reduced in ZPK/DLK-deficient mice}

We next examined whether the increase in motoneurons in ZPK/DLK-deficient mice was a consequence of reduced motoneuron NPCD during embryogenesis. The cells committed to motoneurons in the spinal cord were identified by nuclear immunoreactivity for the homeobox transcription factor HB9 (also known as MNX1 and MNR2) (Arber et al., 1999). At embryonic day (E)12.5, there was no quantitative difference in HB9-positive cells between ZPK/DLK-deficient and wild-type
Table 1. Motoneuron NPCD was reduced in ZPK-deficient embryos compared with wild-type littermates

\begin{tabular}{|c|c|c|c|c|}
\hline & $\begin{array}{l}\text { Embryonic } \\
\text { age }\end{array}$ & $+/+$ & $t p / t p$ & $\begin{array}{l}p \text { value } \\
\text { (Welch's } \\
\text { unpaired } \\
t \text { test) }\end{array}$ \\
\hline \multicolumn{5}{|l|}{ Cervical level } \\
\hline $\mathrm{HB9}^{+}$cells & E12.5 & $40 \pm 4(n=4)$ & $42 \pm 4(n=3)$ & 0.60 \\
\hline $\begin{array}{l}\mathrm{HB9}^{+} \text {cells } \\
\text { Cleaved caspase- } 3^{+}\end{array}$ & E13.5 & $25 \pm 4(n=4)$ & $37 \pm 6(n=4)$ & 0.020 \\
\hline $\begin{array}{l}\text { cells } \\
\text { Cleaved caspase- } 3^{+}\end{array}$ & E12.5 & $5.3 \pm 1.3(n=4)$ & $1.6 \pm 0.4(n=3)$ & 0.006 \\
\hline cells & E13.5 & $9.2 \pm 3.2(n=4)$ & $1.7 \pm 0.5(n=4)$ & 0.017 \\
\hline \multicolumn{5}{|l|}{ Lumber level } \\
\hline $\mathrm{HB9}^{+}$cells & E12.5 & $61 \pm 13(n=3)$ & $61 \pm 3(n=3)$ & 0.94 \\
\hline $\begin{array}{l}\mathrm{HB9}^{+} \text {cells } \\
\text { Cleaved caspase- } 3^{+}\end{array}$ & E13.5 & $31 \pm 7(n=5)$ & $43 \pm 2(n=4)$ & 0.017 \\
\hline $\begin{array}{l}\text { cells } \\
\text { Cleaved caspase- } 3^{+}\end{array}$ & E12.5 & $1.8 \pm 0.8(n=3)$ & $0.8 \pm 0.5(n=3)$ & 0.13 \\
\hline $\begin{array}{l}\text { cells } \\
\text { Cleaved caspase- } 3^{+}\end{array}$ & E13.5 & $4.6 \pm 1.4(n=5)$ & $1.4 \pm 0.6(n=4)$ & 0.004 \\
\hline cells & E16.5 & $0.3 \pm 0.3(n=3)$ & $0.3 \pm 0.2(n=3)$ & 0.92 \\
\hline
\end{tabular}

Quantitative results for $\mathrm{HB}^{+}{ }^{+}$cells and cleaved caspase- $3^{+}$cells within the HB9 ${ }^{+}$motoneuron pool per $6-\mu \mathrm{m}-$ thick section of the ventral spinal cord on one side. Data are means $\pm 1 S D$. More than eight sections per animal were counted. $n$, Number of animals examined; tp/tp, ZPK-deficient; $+/+$, wild-type.

embryos, indicating that motoneuron specification was not enhanced by loss of ZPK/DLK. In wild-type embryos, cleaved caspase-3-postive apoptotic cells in the HB9-positive motoneuron cluster became apparent at the cervical spinal levels at E12.5, and at the lumbar levels at E13.5, followed by a reduction of HB9-positive cells. In contrast, motoneuron NPCD in ZPK/ DLK-deficient embryos remained significantly less than that in wild-type embryos. At E16.5, motoneuron NPCD was completed in wild-type embryos, and no delayed NPCD was observed in ZPK/DLK-deficient embryos (Fig. $1 F$, Table 1).

\section{No remarkable abnormalities in the muscles and neuromuscular junctions of ZPK/DLK-deficient mice}

Enhanced survival of motoneurons in ZPK/DLK-deficient mice might be associated with aberrant development of muscles and/or neuromuscular junctions (NMJs). To address this, we analyzed the diaphragm and the phrenic nerve. No gross anatomical abnormalities were found in the diaphragm or the phrenic nerve of ZPK/DLK-deficient E16.5 embryos (Fig. 2). Averaged NMJ densities calculated from the multiple confocal images (Fig. $2 E, F)$ of the diaphragm were $24 \pm 8(n=4)$ and $24 \pm 6(n=3)$ per $100 \mu \mathrm{m}$ of the long axis of the NMJ clusters in ZPK/DLKdeficient and wild-type E16.5 embryos, respectively $(p>0.05)$ and no multiple innervation was found in PN21 ZPK/DLKdeficient mice (90 NMJs were examined) (Fig. 2G,H). From these results, we hypothesized that excess motoneurons remained viable even though their axons failed to reach the target in ZPK/ DLK-deficient mice. In support of this hypothesis, myelinated axons in the proximal portion of the phrenic nerve were always more than those in the distal portion in ZPK/DLK-deficient mice at PN21. Since no aberrant branches were observed between the two portions examined, this result suggests that some excess myelinated axons present in the proximal portion failed to reach the distal portion in the ZPK/DLK-deficient phrenic nerve. In clear contrast, such quantitative mismatch between proximal and distal myelinated axons was never found in wild-type phrenic nerves (Fig. 3). 


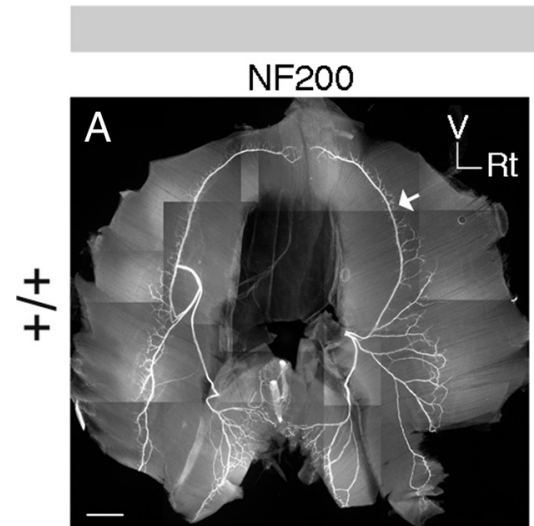

\section{E16.5}
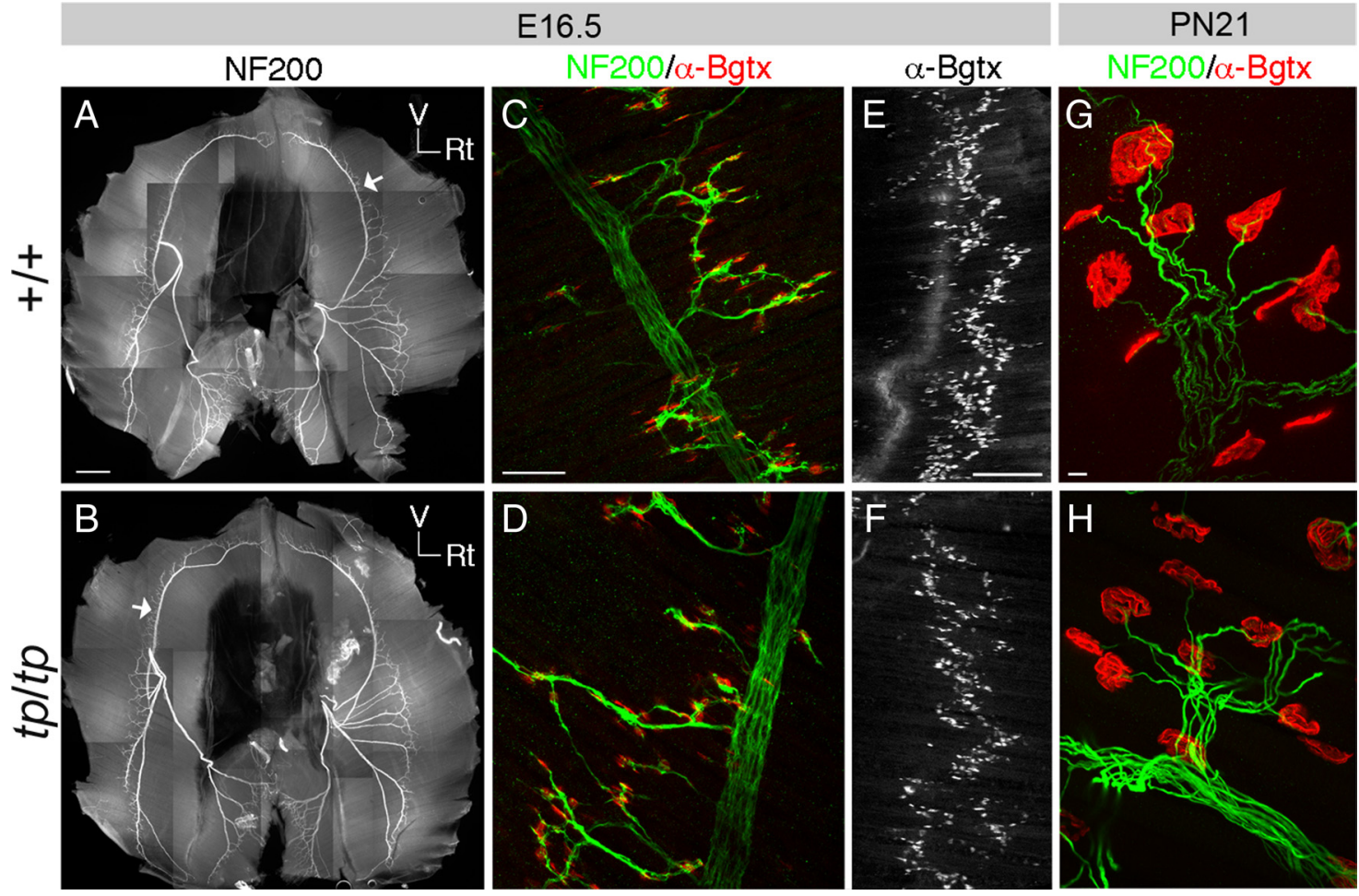

Figure 2. Innervation of the diaphragm by the phrenic nerve was indistinguishable between ZPK/DLK-deficient and wild-type mice. Whole-mount diaphragms and distal phrenic nerves from wild-type $(+/+$ ) and ZPK/DLK-deficient (tp/tp) embryos at E16.5 were immunolabeled for NF200 (green) and $\alpha$-bungarotoxin ( $\alpha$-Bgtx, red). Arrows in $A$ and $B$ indicate areas magnified in $C$ and $\boldsymbol{D}$, respectively, to demonstrate terminal branching of the phrenic nerve and neuromuscular junctions. $\boldsymbol{E}$, $\boldsymbol{F}$, Representative Z-stacked confocal images of the $\alpha$-bungarotoxin-labeled neuromuscular junctions from the bottom to top surfaces of the diaphragm from wild-type $(\boldsymbol{E})$ and ZPK/DLK-deficient $(\boldsymbol{F})$ E16.5 embryos demonstrate no obvious increase in clustering of neuromuscular junctions. At PN21, all of the neuromuscular junctions examined were innervated by a single axon in the diaphragms of both ZPK/DLK-deficient $(\boldsymbol{H})$ and wild-type $(\boldsymbol{G})$ mice. Representative pictures are shown. Scale bars: $\boldsymbol{A}, \boldsymbol{B}$ (in $\boldsymbol{A}$ ), $500 \mu \mathrm{m} ; \boldsymbol{C}-\boldsymbol{F}$ (in $\boldsymbol{C}, \boldsymbol{E}) 100 \mu \mathrm{m} ; \boldsymbol{G}, \boldsymbol{H}$ (in $\boldsymbol{G}), 10 \mu \mathrm{m}$ V, Ventral; Rt, right.

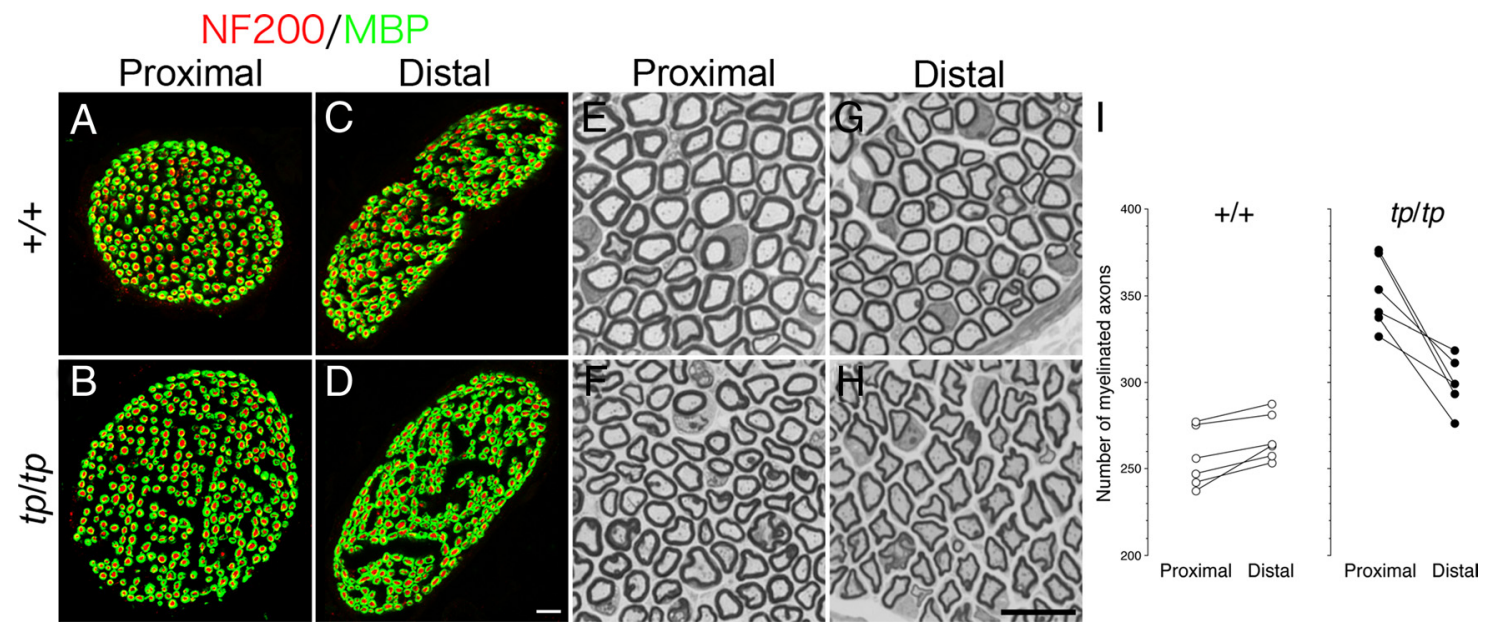

Figure 3. ZPK/DLK-deficient mice had more myelinated axons in the proximal portion of the phrenic nerve than in the distal portion. $\boldsymbol{A}-\boldsymbol{D}$, Representative confocal laser micrographs of proximal $(\boldsymbol{A}, \boldsymbol{B})$ and distal $(C, D)$ portions of the wild-type $(+/+)$ andZPK/DLK-deficient $(t p / t p)$ phrenic nerves immunolabeled for MBP and NF200. The proximal portion was at the level of the aortic arch and the distal portion was immediately proximal of the first major trifurcation of the phrenicnerveadjacent to the diaphragm. $\boldsymbol{E}-\boldsymbol{H}$, Methylene blue-stained $1-\mu \mathrm{m}$-thick cross-sections of the proximal portions $(\boldsymbol{E}$, $\boldsymbol{F})$ and the distal portions $(\boldsymbol{G}, \boldsymbol{H})$ of the phrenicnerves from wild-type $(\boldsymbol{E}, \boldsymbol{G})$ andZPK/DLK-deficient $(\boldsymbol{F}, \boldsymbol{H})$ mice. Representative high-power images demonstrate that the distal portion of the phrenic nervefrom aZPK/DLK-deficientmouse was primarily composed of large-diameter myelinated axons, which were indistinguishable from that from a wild-type mouse. $I$, Quantitative analysis of myelinated axon numbers in the phrenic nerves from ZPK/DLK-deficient (closed circles, $t p / t p$ ) and wild-type (open circles, $+/+$ ) mice at PN21. Each pair of the connected circles represents the myelinated axon numbers at the proximal and distal portions of a phrenic nerve. Left and right phrenic nerves from three mice were quantified in each genotype. Scale bars, $100 \mu \mathrm{m}$.

\section{Discussion}

A series of studies proved that establishment of axonal connection to the target muscle suppresses NPCD in motoneurons through interaction between axon terminals and a combination of muscle-derived molecules (Oppenheim, 1996; Calderó et al.,
1998; Grieshammer et al., 1998). In developing sympathetic neurons and differentiated $\mathrm{PC} 12$ pheochromocytoma cells, prototypical models of NPCD, deprivation of nerve growth factor (NGF) elicits activation of a pathway serially involving the small GTP-binding protein Rac1/Cdc42, MLKs, MKK4, MKK7, JNKs, 
and c-JUN, resulting in activation of the intrinsic apoptotic pathway (Wang et al., 2004). A similar molecular pathway involving MLKs, JNKs, and c-JUN has been shown to underlie NPCD of motoneurons (Maroney et al., 1998; Sun et al., 2005; Ribera et al., 2007). Our study further indicates that motoneurons are largely dependent on ZPK/DLK to mediate NPCD signaling, whereas sympathetic neurons use a spectrum of MLKs such as MLK3 and ASK1 for NPCD (Kanamoto et al., 2000; Mota et al., 2001; Xu et al., 2001). Unlike motoneurons, we found only a small difference in the numbers of primary sensory neurons between ZPK/DLKdeficient and wild-type mice in a previous study (Itoh et al., 2009), supporting the notion that each neuron system uses a distinct set of MLKs for NPCD.

Activation of the intrinsic apoptotic pathway is a key event before the execution phase of NPCD in motoneurons. BAX and BAK, multidomain proapoptotic members of the Bcl-2-related protein family, act as a checkpoint through which death signals activate the intrinsic apoptotic pathway (Wei et al., 2001). Indeed, NPCD of motoneurons is virtually absent in BAX-deficient mice during development (Deckwerth et al., 1996; White et al., 1998). Detailed analysis of BAX-deficient motoneurons by Sun et al. (2003) revealed, however, that, though rescued from NPCD, these motoneurons became so severely atrophic postnatally that they could no longer be securely identified as motoneurons in Nissl-stained sections. This observation is in line with our results in BAX- and BAK-double-deficient oligodendrocytes (Kawai et al., 2009), but clearly contrasts with the healthy-appearing excess motoneurons in ZPK/DLK-deficient mice. Similarly, Harris et al. (2002) reported that CEP-1347 preserved metabolism and growth of sympathetic neurons deprived of NGF. Those results, together with our observations in ZPK/DLK-deficient mice, indicate that loss of BAX dissociates competence-to-die from metabolic downregulation during the execution phase of NPCD, whereas ZPK/DLK is likely to be upstream of both processes. These atrophic changes, particularly axonal degeneration of the motoneurons committed to NPCD, might be associated with the recent observation by Miller et al. (2009) that ZPK/DLK mediates the axon self-destruction program in Wallerian degeneration. Furthermore, recent studies have shown that DLK-1 and Wallenda, the invertebrate ZPK/DLK homologues, play a critical role in axon autonomous responses to various exogenous stimuli, such as terminal formation and axon regeneration and degeneration, by regulating local protein synthesis and degradation in axons (Nakata et al., 2005; Collins et al., 2006; Hammarlund et al., 2009; Yan et al., 2009). Loss of these ZPK/DLK-mediated axon autonomous mechanisms therefore might contribute to the axon preservation of excess motoneurons and enhance their survival in ZPK/DLK-deficient mice.

There is growing evidence that activation of the apoptotic machinery plays a role not only in NPCD but also in neurodegenerative diseases such as Parkinson's disease (Silva et al., 2005). Since our results suggest that each neuron system uses a distinct set of MLKs depending on exogenous signals, MLK inhibitors more selective for ZPK/DLK rather than other MLKs might promote survival of motoneurons in certain types of motor neuron diseases.

\section{References}

Arber S, Han B, Mendelsohn M, Smith M, Jessell TM, Sockanathan S (1999) Requirement for the homeobox gene $\mathrm{Hb} 9$ in the consolidation of motor neuron identity. Neuron 23:659-674.

Calderó J, Prevette D, Mei X, Oakley RA, Li L, Milligan C, Houenou L, Burek M, Oppenheim RW (1998) Peripheral target regulation of the develop- ment and survival of spinal sensory and motor neurons in the chick embryo. J Neurosci 18:356-370.

Chen X, Rzhetskaya M, Kareva T, Bland R, During MJ, Tank AW, Kholodilov N, Burke RE (2008) Antiapoptotic and trophic effects of dominantnegative forms of dual leucine zipper kinase in dopamine neurons of the substantia nigra in vivo. J Neurosci 28:672-680.

Collins CA, Wairkar YP, Johnson SL, DiAntonio A (2006) Highwire restrains synaptic growth by attenuating a MAP kinase signal. Neuron 51:57-69.

Deckwerth TL, Elliott JL, Knudson CM, Johnson EM Jr, Snider WD, Korsmeyer SJ (1996) BAX is required for neuronal death after trophic factor deprivation and during development. Neuron 17:401-411.

Fan G, Merritt SE, Kortenjann M, Shaw PE, Holzman LB (1996) Dual leucine zipper-bearing kinase (DLK) activates $\mathrm{p} 46^{\mathrm{SAPK}}$ and $\mathrm{p} 38^{\text {mapk }}$ but not ERK2. J Biol Chem 271:24788-24793.

Gallo KA, Johnson GL (2002) Mixed-lineage kinase control of JNK and p38 MAPK pathways. Nat Rev Mol Cell Biol 3:663-672.

Glicksman MA, Chiu AY, Dionne CA, Harty M, Kaneko M, Murakata C, Oppenheim RW, Prevette D, Sengelaub DR, Vaught JL, Neff NT (1998) CEP-1347/KT7515 prevents motor neuronal programmed cell death and injury-induced dedifferentiation in vivo. J Neurobiol 35:361-370.

Grieshammer U, Lewandoski M, Prevette D, Oppenheim RW, Martin GR (1998) Muscle-specific cell ablation conditional upon Cre-mediated DNA recombination in transgenic mice leads to massive spinal and cranial motoneuron loss. Dev Biol 197:234-247.

Hamburger V (1975) Cell death in the development of the lateral motor column of the chick embryo. J Comp Neurol 160:535-546.

Hammarlund M, Nix P, Hauth L, Jorgensen EM, Bastiani M (2009) Axon regeneration requires a conserved MAP kinase pathway. Science 323:802-806.

Harris CA, Deshmukh M, Tsui-Pierchala B, Maroney AC, Johnson EM Jr (2002) Inhibition of the c-Jun $N$-terminal kinase signaling pathway by the mixed lineage kinase inhibitor CEP-1347 (KT7515) preserves metabolism and growth of trophic factor-deprived neurons. J Neurosci 22:103-113.

Hirai S, Izawa M, Osada S, Spyrou G, Ohno S (1996) Activation of the JNK pathway by distantly related protein kinases, MEKK and MUK. Oncogene 12:641-650.

Hirai S, Kawaguchi A, Hirasawa R, Baba M, Ohnishi T, Ohno S (2002) MAPK-upstream protein kinase (MUK) regulates the radial migration of immature neurons in telencephalon of mouse embryo. Development 129:4483-4495.

Hirai S, Cui de F, Miyata T, Ogawa M, Kiyonari H, Suda Y, Aizawa S, Banba Y, Ohno S (2006) The c-Jun $N$-terminal kinase activator dual leucine zipper kinase regulates axon growth and neuronal migration in the developing cerebral cortex. J Neurosci 26:11992-12002.

Holzman LB, Merritt SE, Fan G (1994) Identification, molecular cloning, and characterization of dual leucine zipper bearing kinase. J Biol Chem 269:30808-30817.

Itoh A, Horiuchi M, Bannerman P, Pleasure D, Itoh T (2009) Impaired regenerative response of primary sensory neurons in ZPK/DLK gene-trap mice. Biochem Biophys Res Commun 383:258-262.

Kanamoto T, Mota M, Takeda K, Rubin LL, Miyazono K, Ichijo H, Bazenet CE (2000) Role of apoptosis signal-regulating kinase in regulation of the c-Jun $\mathrm{N}$-terminal kinase pathway and apoptosis in sympathetic neurons. Mol Cell Biol 20:196-204.

Kawai K, Itoh T, Itoh A, Horiuchi M, Wakayama K, Bannerman P, Garbern JY, Pleasure D, Lindsten T (2009) Maintenance of the relative proportion of oligodendrocytes to axons even in the absence of BAX and BAK. Eur J Neurosci 30:2030-2041.

Maroney AC, Glicksman MA, Basma AN, Walton KM, Knight E Jr, Murphy CA, Bartlett BA, Finn JP, Angeles T, Matsuda Y, Neff NT, Dionne CA (1998) Motoneuron apoptosis is blocked by CEP-1347 (KT 7515), a novel inhibitor of the JNK signaling pathway. J Neurosci 18:104-111.

Miller BR, Press C, Daniels RW, Sasaki Y, Milbrandt J, DiAntonio A (2009) A dual leucine kinase-dependent axon self-destruction program promotes Wallerian degeneration. Nat Neurosci 12:387-389.

Mota M, Reeder M, Chernoff J, Bazenet CE (2001) Evidence for a role of mixed lineage kinases in neuronal apoptosis. J Neurosci 21:4949-4957.

Murakata C, Kaneko M, Gessner G, Angeles TS, Ator MA, O’Kane TM, McKenna BA, Thomas BA, Mathiasen JR, Saporito MS, Bozyczko-Coyne D, 
Hudkins RL (2002) Mixed lineage kinase activity of indolocarbazole analogues. Bioorg Med Chem Lett 12:147-150.

Nakata K, Abrams B, Grill B, Goncharov A, Huang X, Chisholm AD, Jin Y (2005) Regulation of a DLK-1 and p38 MAP kinase pathway by the ubiquitin ligase RPM-1 is required for presynaptic development. Cell 120:407-420.

Oppenheim RW (1991) Cell death during development of the nervous system. Annu Rev Neurosci 14:453-501.

Oppenheim RW (1996) Neurotrophic survival molecules for motoneurons: an embarrassment of riches. Neuron 17:195-197.

Putcha GV, Johnson EM Jr (2004) 'Men are but worms:' neuronal cell death in C. elegans and vertebrates. Cell Death Differ 11:38-48.

Reddy UR, Pleasure D (1994) Cloning of a novel putative protein kinase having a leucine zipper domain from human brain. Biochem Biophys Res Commun 202:613-620.

Ribera J, Ayala V, Casas C (2007) Involvement of c-Jun-JNK pathways in the regulation of programmed cell death of developing chick embryo spinal cord motoneurons. Dev Neurosci 29:438-451.

Roux PP, Dorval G, Boudreau M, Angers-Loustau A, Morris SJ, Makkerh J, Barker PA (2002) K252a and CEP1347 are neuroprotective compounds that inhibit mixed-lineage kinase- 3 and induce activation of Akt and ERK. J Biol Chem 277:49473-49480.

Silva RM, Kuan CY, Rakic P, Burke RE (2005) Mixed lineage kinase-c-jun $\mathrm{N}$-terminal kinase signaling pathway: a new therapeutic target in Parkinson's disease. Mov Disord 20:653-664.

Sun W, Gould TW, Vinsant S, Prevette D, Oppenheim RW (2003) Neuro- muscular development after the prevention of naturally occurring neuronal death by Bax deletion. J Neurosci 23:7298-7310.

Sun W, Gould TW, Newbern J, Milligan C, Choi SY, Kim H, Oppenheim RW (2005) Phosphorylation of c-Jun in avian and mammalian motoneurons in vivo during programmed cell death: an early reversible event in the apoptotic cascade. J Neurosci 25:5595-5603.

Wang LH, Besirli CG, Johnson EM Jr (2004) Mixed-lineage kinases: a target for the prevention of neurodegeneration. Annu Rev Pharmacol Toxicol 44:451-474.

Wei MC, Zong WX, Cheng EH, Lindsten T, Panoutsakopoulou V, Ross AJ, Roth KA, MacGregor GR, Thompson CB, Korsmeyer SJ (2001) Proapoptotic BAX and BAK: a requisite gateway to mitochondrial dysfunction and death. Science 292:727-730

White FA, Keller-Peck CR, Knudson CM, Korsmeyer SJ, Snider WD (1998) Widespread elimination of naturally occurring neuronal death in Baxdeficient mice. J Neurosci 18:1428-1439.

Xu Z, Maroney AC, Dobrzanski P, Kukekov NV, Greene LA (2001) The MLK family mediates c-Jun $N$-terminal kinase activation in neuronal apoptosis. Mol Cell Biol 21:4713-4724.

Yamamoto Y, Henderson CE (1999) Patterns of programmed cell death in populations of developing spinal motoneurons in chicken, mouse, and rat. Dev Biol 214:60-71.

Yan D, Wu Z, Chisholm AD, Jin Y (2009) The DLK-1 kinase promotes mRNA stability and local translation in C. elegans synapses and axon regeneration. Cell 138:1005-1018. 